\author{
Bull. of Egyp. Soc. Physiol. Sci. \\ (Official Journal of Egyptian Society for Physiological Sciences) \\ (pISSN: 1110-0842; eISSN: 2356-9514)
}

\title{
L-arginine supplementation reduces blood pressure and plasma lipid levels in an animal model of perimenopause induced by 4-Vinylcyclohexene diepoxide
}

\author{
Adesina Arikawe $^{1}$, Adedunni Olusanya ${ }^{2}$, Ifeoma Udenze ${ }^{3}$, Olutope Akinnibosun ${ }^{1}$,
}

\section{Abdullahi Adejare ${ }^{1}$, Odunayo Olumide ${ }^{4}$, Ibiyemi Olatunji-Bello ${ }^{4}$, and Janete Anselmo-Franci ${ }^{5}$.}

${ }^{1}$ Department of Physiology, Faculty of Basic Medical Sciences, ${ }^{2}$ Department of Pharmacology, Therapeutics \& Toxicology, Faculty of Basic Medical Sciences, ${ }^{3}$ Department of Clinical Pathology, Faculty of Clinical Sciences, College of Medicine, University of Lagos, Idi-Araba, ${ }^{4}$ Department of Physiology, Faculty of Basic Medical Sciences, Lagos State University, Ikeja, Lagos, Nigeria, ${ }^{5}$ Laboratory of Neuroendocrinology, Department of Morphology, Physiology and Basic Pathology, School of Dentistry of Ribeirão Preto, University of São Paulo, São Paulo, Brazil.

Received: 20 Nov 2018 Accepted: 1 Feb 2019

Available online: 1 mar 2019

\section{Keywords}

- Perimenopause

- L-arginine

- Blood pressure

- Lipid profile

\begin{abstract}
The incidence of women developing high blood pressure during perimenopause has been documented and is sustained till menopause. However, no study till date on beneficial effects of L-arginine supplementation on BP during perimenopause in humans and animal models of perimenopause. Female rats 28 days old were divided into 3 groups; Control group was injected (SC) daily with Corn oil $(2.5 \mu \mathrm{l} / \mathrm{g} \mathrm{BW})$ for 15 days, allowed to grow till $12^{\text {th }}$ week; VCD group was injected (SC) daily with 4-vinylcyclohexene diepoxide (160 mg/kg BW) diluted in Corn oil (2.5 $\mu \mathrm{l} / \mathrm{g} \mathrm{BW})$ for 15 days, allowed to grow till $12^{\text {th }}$ week; VCD $+\mathrm{L}-\mathrm{ARG}$ group was injected as VCD group, allowed to grow till $8^{\text {th }}$ week, then administered oral $100 \mathrm{mg} / \mathrm{kg} \mathrm{L}$-arginine daily for additional 4 weeks. Caudal BP was measured with tail-cuff apparatus (Kent Scientific CODA system) at weeks eight, ten, and twelve. Terminal BP was also measured with a power-lab apparatus and blood samples were subsequently collected for measurement of plasma lipid profile. L-arginine supplementation significantly reduced systolic, diastolic and mean arterial BP parameters in the VCD + L-ARG group compared to the Control and VCD groups $(\mathrm{P}<0.05)$. It also significantly reduced total cholesterol and LDL concentrations in the VCD + L-ARG group compared to the Control and VCD groups $(\mathrm{P}<0.05)$. HDL concentration was significantly higher in the VCD and VCD + L-ARG groups compared to the Control group $(\mathrm{P}<0.05)$. These results show that L-arginine supplementation ameliorates some cardiovascular risk factors during perimenopausal transitory period.
\end{abstract}

"Dr. Adesina Paul Arikawe Senior Lecturer Clinical and Neuroendocrine Physiology Unit, Department of Physiology, Faculty of Basic Medical Sciences College of Medicine, University of Lagos, Idi Araba, Lagos, Nigeria. Email: arikawepaul2002@yahoo.co.uk and aarikawe@ unilag.edu.ng Phone number: +234 8060547105 


\section{INTRODUCTION}

Major hormonal transition periods characterize a woman's life span, commencing at puberty with rising estrogen levels, which remain high during pregnancy followed by a rapid decline postpartum, gradual decrease in perimenopause, and even lower levels in the menopausal stage [13]. Perimenopause, a phase where the body transitions towards menopause involves changes in ovarian hormones, quantity and quality of ovarian follicles, feedback relationships and clinical experiences beginning mid-life in women around age $35-50$ years with regular flow ending 1 year after the final menstrual flow [4-5].

In the human population, systematic evaluation of the biological processes associated with menopausal transition can be challenging, hence rodent animal models have become crucial in gaining an understanding to the essential elements driving the reproductive and aging processes [6]. The 4-Vinylcyclohexene diepoxide (VCD) rodent model of transitional menopause has a significant edge above the natural aging (ovary intact) or ovariectomized models, because it closely resembles the perimenopausal period, having comparable circulating steroid hormone profile and preserved ovarian tissue, although resting follicle pool is depleted [6]. The VCD model of perimenopause eliminates the sudden halt of circulating ovarian hormones as seen in ovariectomized rats while ensuring a decrease ovarian function in rats as early as around 60 days of age [6-8].

The reduced risk of development of coronary heart disease in women compared to men is nullified during the menopause transition [9-
10]. Numerous studies have shown the association between perimenopause and altered lipid profile including elevated levels of total cholesterol (TC), triglycerides (TG) and low-density lipoprotein cholesterol (LDL-C), and reduced high density lipoprotein cholesterol (HDL-C) levels, thereby increasing CVD risk [11-13]. It has been proposed that reduced estrogen concentrations in this period might be responsible for the alterations in lipid profile seen in perimenopause $[11,14]$.

L-arginine a precursor for the synthesis of nitric oxide (NO) is an amino acid that play multiple roles in the cardiovascular system largely through NO production [15-17]. Several studies have established the antihypertensive and antioxidant properties of L-arginine, showing the benefits in hypertension and hypercholesterolemia [15, 18-24)]. L-arginine supplementation has been shown to reduce $\mathrm{BP}$ and related cardiovascular risk factors in humans and animals. The incidence of women at high risk of cardiovascular diseases during perimenopause has also been documented and there is evidence this is sustained till menopause. There is paucity of data on the beneficial effects of $\mathrm{L}$-arginine supplementation on cardiovascular risk factors during perimenopause in humans and its animal models. Hence this study aimed to assess beneficial effects of oral Larginine on some cardiovascular risk factors (hypertension and dyslipidaemia) during this transitory period using a VCD induced animal model.

\section{Materials and Methods}

\section{Chemicals}

4-vinylcyclohexene diepoxide (VCD) was purchased from Sigma-Aldrich (St. Louis, MO, 
USA). Enzymatic colorimetric assay for the quantification of triacylglycerol and total cholesterol were from Biotécnica (Varginha, MG, Brazil). L-arginine was purchased from Nowfoods (USA).

\section{Animals}

\subsection{Experimental animals and diet}

Thirty female Sprague-Dawley rats at 28 days of age were obtained from the animal laboratory center, College of Medicine, University of Lagos. All the animals were housed in groups of 5 rats per clear polypropylene cage lined with wood shavings and acclimatized for one week. Rats were kept under normal light conditions (12 hours light/dark cycle) and normal room temperature $\left(23 \pm 1{ }^{\circ} \mathrm{C}\right)$. Pelletized normal rat chow and water was made available ad libitum, and all rats were weighed weekly. All experimental procedures were carried out in compliance with the international principles for laboratory animals as obtained in the Helsinki's declaration (NIH1985) guide for care and use of laboratory animals. The research protocol was also in line with the guidelines of the College of Medicine, University of Lagos, Health Research Ethics Committee.

\subsection{Experimental design and animal groupings}

Post-weaned rats were acclimatized for a week and then randomly divided into three groups as follows: Group I (Control) received daily subcutaneous injection of corn oil $(2.5 \mu \mathrm{l} / \mathrm{g}$ BW) for 15 consecutive days and allowed to grow till the $12^{\text {th }}$ week. Group II (VCD) received daily subcutaneous injection of VCD $(160 \mathrm{mg} / \mathrm{Kg})[25-$ 26] diluted in Corn oil $(2.5 \mu \mathrm{l} / \mathrm{g}$ BW) for 15 consecutive days and also allowed to grow till the $12^{\text {th }}$ week. Group III (VCD + L-ARG) received daily subcutaneous injection of VCD $(160 \mathrm{mg} / \mathrm{Kg}$, BW) as in Group II above, allowed to grow till $8^{\text {th }}$ week (i.e. 8 weeks after VCD administration), after which, $100 \mathrm{mg} / \mathrm{kg}$ of L-arginine in distilled water was orally administered daily via oral cannula to rats in this group for additional duration of 4 weeks. The average age of rats in each group was 128 days and 12 weeks as stated above signified the number of weeks after either corn oil or VCD administration.

\section{Measurement of Cardiovascular parameters}

\subsection{Non-invasive blood pressure measurement}

Once every two weeks at the $8^{\text {th }}$ week, $10^{\text {th }}$ week and $12^{\text {th }}$ week blood pressure parameters were recorded in all the three groups using tailcuff (non-invasive) apparatus from Kent Scientific CODA system (Coda HT system with 4 activated channels, CODA-HT4). We have previously observed that female rats injected with VCD usually transit towards reproductive senescence from 80 to 100 days of age (yet to be published data). Beginning from the $8^{\text {th }}$ week, animals in each group were aged within 80 to 100 days as stated above. Also non-invasive blood pressure parameters were measured from the $8^{\text {th }}$ week till the $12^{\text {th }}$ week to establish a pattern during this transitory period in female rats.

\subsection{Invasive blood pressure measurement}

Invasive BP parameters were measured using the Powerlab instrument. Briefly, at the end of the $12^{\text {th }}$ week, rats were fasted overnight and anaesthetized with $\quad 1200 \mathrm{mg} / \mathrm{kg} \quad$ urethane injected intraperitoneally. The reflexes of the animals were checked, and subsequently placed on a suitable rodent surgical table. The femoral vein was 
cannulated for saline administration with the skin on ventral side of the neck, right hind leg, and chest carefully shaved and disinfected. An incision $(1-2 \mathrm{~cm})$ was made in the epidermis (outer layer of the skin) of the right thigh, and the matrix of collagen fibers interlaced with elastic fibers of the dermis was cleaned carefully. A small incision $(1.5-2 \mathrm{~cm})$ was made in the neck of the rat for tracheostomy and carotid artery cannulation. The skin in the neck region was carefully cut open, and a slit incision made in the rat platysma muscles. The trachea was identified, small incision made on its cartilage tissue, and the tracheostomy was carried out using a small piece of rodent tracheal intubation tube.

The carotid artery was identified along with the vagus nerve and cannulated using a cannula pre-filled with heparinized normal saline $(0.5 \mathrm{IU} / \mathrm{ml})$ with the other end of the cannula connected to a three-way stopcock/saline filled tuberculin syringe and the animal connected to the power lab machine to record the BP parameters.

\section{Blood sampling}

Blood samples were collected from each rat immediately after invasive recording of $\mathrm{BP}$ parameters according to animal groupings and markings. The blood samples were collected from the left carotid artery using a capillary tube, collected into EDTA coated test tubes and centrifuged at $3000(\mathrm{rpm})$ for $10 \mathrm{mins}$ to extract the plasma. The plasma was stored at $-80^{\circ} \mathrm{C}$ for measurement of the fasting lipid profile.

\section{Fasting lipid profile assessment}

Plasma concentrations of total cholesterol (TC), High density lipoprotein (HDL), Low density lipoprotein (LDL), and triglyceride (TG) were measured by enzymatic-colorimetric assay using commercial kits (Biotécnica, Varginha, MG, Brazil). Atherogenic fraction (AF) was calculated as the difference between TC and HDL. Increased $\mathrm{AF}$ is one of the indicators of cardiovascular risk.

\section{Statistical analysis}

All results were expressed as mean \pm SEM. Data were analyzed using GraphPad Prism version 8.0 (GraphPad software San Diego, California, USA). Statistical analysis of the data was performed using one-way analysis of variance (ANOVA) followed by student-Newman-Keuls post- hoc test. The differences among the three groups were analyzed using Tukey's Multiple Comparison test. Values of $\mathrm{P}<0.05$ were considered statistically significant.

\section{Results}

\section{Cardiovascular Parameters}

Tables $(1-3)$ show that Systolic blood pressure (SBP), Diastolic blood pressure (DBP), and Mean arterial pressure (MAP) were significantly higher $(\mathrm{P}<0.05)$ in the VCD group compared to the control group. At the $8^{\text {th }}$ week (commencement of L-Arginine administration), there was no significant difference in SBP, DBP and MAP between VCD and VCD + L-ARG groups. However, from the $10^{\text {th }}$ week, SBP, DBP and MAP were significantly lower $(\mathrm{P}<0.05)$ in $\mathrm{VCD}+\mathrm{L}$ ARG group compared to the VCD group. 
Table 1. Systolic Blood Pressure (mmHg) in Control, VCD and VCD + L-ARG groups

\begin{tabular}{|c|c|c|c|c|}
\hline $\begin{array}{c}\text { Grouping } \\
(\mathbf{n}=\mathbf{1 0})\end{array}$ & $\mathbf{8}^{\text {th }}$ week & $\mathbf{1 0}^{\text {th }}$ week & $\mathbf{1 2}^{\text {th }}$ week & Terminal \\
\hline Control & $131.5 \pm 2.75 \mathrm{mmHg}$ & $137.6 \pm 1.41 \mathrm{mmHg}$ & $127.8 \pm 2.41 \mathrm{mmHg}$ & $104.3 \pm 2.01 \mathrm{mmHg}$ \\
\hline VCD & $155.71 \pm 3.65 * \mathrm{mmHg}$ & $150.9 \pm 1.10 * \mathrm{mmHg}$ & $160.0 \pm 3.40 * \mathrm{mmHg}$ & $119.2 \pm 2.52 * \mathrm{mmHg}$ \\
\hline VCD + L-ARG & $157.17 \pm 2.48 * \mathrm{mmHg}$ & $116.9 \pm 1.50 \alpha \mathrm{mmHg}$ & $105.4 \pm 3.87 * \alpha \mathrm{mmHg}$ & $101.2 \pm 232 \alpha \mathrm{mmHg}$ \\
\hline
\end{tabular}

All results are expressed as mean \pm SEM. One-way ANOVA with student-Newman-Keuls post hoc test. *P $<0.05$ Vs. Control, $\alpha \mathrm{P}<0.05$ Vs VCD.

Table 2. Diastolic Blood Pressure (mmHg) in Control, VCD and VCD + L-ARG groups

\begin{tabular}{|c|c|c|c|c|}
\hline $\begin{array}{c}\text { Grouping } \\
(\mathbf{n}=\mathbf{1 0})\end{array}$ & $\mathbf{8}^{\text {th }}$ week & $\mathbf{1 0}^{\text {th }}$ week & $\mathbf{1 2}^{\text {th }}$ week & Terminal \\
\hline Control & $102.1 \pm 2.75 \mathrm{mmHg}$ & $109.6 \pm 2.02 \mathrm{mmHg}$ & $92.2 \pm 1.65 \mathrm{mmHg}$ & $80.1 \pm 2.42 \mathrm{mmHg}$ \\
\hline VCD & $125.5 \pm 2.12 * \mathrm{mmHg}$ & $124.7 \pm 3.46^{*} \mathrm{mmHg}$ & $112.4 \pm 2.14 * \mathrm{mmHg}$ & $102.9 \pm 3.12 * \mathrm{mmHg}$ \\
\hline VCD + L-ARG & $130.11 \pm 2.48 * \mathrm{mmHg}$ & $90.3 \pm 2.35^{*} \alpha \mathrm{mmHg}$ & $83.8 \pm 1.74 * \alpha \mathrm{mmHg}$ & $84.0 \pm 3.87 \alpha \mathrm{mmHg}$ \\
\hline
\end{tabular}

All results are expressed as mean \pm SEM. One-way ANOVA with student-Newman-Keuls post hoc test. *P $<0.05$ Vs. Control, $\alpha \mathrm{P}<0.05 \mathrm{Vs}$ VCD.

Table 3. Mean Arterial Pressure (mmHg) in Control, VCD and VCD + L-ARG groups.

\begin{tabular}{|c|c|c|c|c|}
\hline $\begin{array}{c}\text { Grouping } \\
(\mathbf{n = 1 0})\end{array}$ & $\mathbf{8}^{\text {th }}$ week & $\mathbf{1 0}^{\text {th }}$ week & $\mathbf{1 2}^{\text {th }}$ week & Terminal \\
\hline Control & $114 \pm 2.75 \mathrm{mmHg}$ & $119.8 \pm 2.38 \mathrm{mmHg}$ & $96.6 \pm 2.62 \mathrm{mmHg}$ & $90.4 \pm 2.12 \mathrm{mmHg}$ \\
\hline VCD & $140.1 \pm 2.48 * \mathrm{mmHg}$ & $133.1 \pm 2.12 * \mathrm{mmHg}$ & $121.7 \pm 4.67 * \mathrm{mmHg}$ & $107.2 \pm 3.64 * \mathrm{mmHg}$ \\
\hline VCD + L-ARG & $138.2 \pm 2.08 * \mathrm{mmHg}$ & $98.8 \pm 2.63 * \alpha \mathrm{mmHg}$ & $92.9 \pm 3.46 * \alpha \mathrm{mmHg}$ & $90.4 \pm 3.06 \alpha \mathrm{mmHg}$ \\
\hline
\end{tabular}

All results are expressed as mean \pm SEM. One-way ANOVA with student-Newman-Keuls post hoc test. *P $<0.05$ Vs.

Control, $\alpha \mathrm{P}<0.05$ Vs VCD.

Table 4. Fasting lipid profile

Table 4 shows that total plasma cholesterol was significantly lower $(\mathrm{P}<0.05)$ in the $\mathrm{VCD}+\mathrm{L}$ ARG group compared to Control and VCD groups. The LDL and atherogenic factor were significantly higher $(\mathrm{P}<0.05)$ in $\mathrm{VCD}$ group compared to Control and VCD + L-ARG groups. HDL was significantly higher $(\mathrm{P}<0.05)$ in VCD and VCD + L-ARG groups compared to Control group. There was no significant difference in triglycerides across the groups. Likewise, there was no significant difference in LDL concentrations between Control and VCD + L-ARG groups.

Table 4. Fasting lipid profile in Control, VCD and VCD + L-ARG groups

\begin{tabular}{|c|c|c|c|}
\hline Grouping (n= 10) & Control & VCD & VCD + L-ARG \\
\hline $\begin{array}{c}\text { Total cholesterol } \\
(\mathrm{mmol} / \mathrm{L})\end{array}$ & $2.42 \pm 0.02$ & $2.43 \pm 0.04$ & $2.15 \pm 0.03^{*} \alpha$ \\
\hline $\begin{array}{c}\text { Triglyceride } \\
(\mathrm{mmol} / \mathrm{L})\end{array}$ & $0.50 \pm 0.03$ & $0.50 \pm 0.05$ & $0.70 \pm 0.07$ \\
\hline $\begin{array}{c}\text { HDL } \\
(\mathrm{mmol} / \mathrm{L})\end{array}$ & $1.00 \pm 0.01$ & $1.30 \pm 0.06^{*}$ & $0.53 \pm 0.05 \alpha$ \\
\hline $\begin{array}{c}\text { LDL } \\
(\mathrm{mmol} / \mathrm{L})\end{array}$ & $0.50 \pm 0.03$ & $0.90 \pm 0.06^{*}$ & $0.78 \pm 0.06 \alpha$ \\
\hline $\begin{array}{c}\text { Atherogenic fraction } \\
(\mathrm{mmol} / \mathrm{L})\end{array}$ & $0.83 \pm 0.04$ & $1.13 \pm 0.07^{*}$ & \\
\hline
\end{tabular}

Fasting lipid profile: Total cholesterol (mmol/L), Triglyceride (mmol/L), HDL (mmol/L), LDL (mmol/L), and Atherogenic factor $(\mathrm{mmol} / \mathrm{L})$. All results are expressed as mean \pm SEM. One-way ANOVA with student-Newman-Keuls post hoc test. $* \mathrm{P}<0.05$ Vs. Control, $\alpha \mathrm{P}<0.05$ Vs VCD. 


\section{Discussion}

The study showed that oral L-arginine administration significantly reduced blood pressure and improved lipid parameters in perimenopausal rats. Significant increases in blood pressure seen in VCD rats in this study was in accordance with previous studies [27-28]. Hypertension is the major risk factor for cardiovascular diseases and increases in blood pressure during perimenopausal has been attributed to decreased estrogen levels [29]. Estrogen has been demonstrated to have a regulatory effect on the blood pressure both centrally and peripherally. It binds to estrogen receptors in the cortex to modulate the action of the RAAS system thus causing a reduction in blood pressure. It also acts via the nitric oxide pathway to stimulate the production of NOS and gender differences in the production of endothelial nitric oxide has been reported [30].

In the periphery, estrogen stimulates the production of nitric oxide by the upregulation of endothelial nitric oxide synthase. Nitric oxide is a vasodilatory molecule and its deficiency is implicated in the in the pathogenesis of hypertension [30].

Studies have shown that nitric oxide levels are significantly lower in menopausal women with hypertension compared to premenopausal hypertensive women, thus implicating reduced nitric oxide in the pathogenesis of menopausal related hypertension [31]. Apart from reduced levels of nitric oxide occurring due to reduced synthesis, there is also increased consumption as a result of increased oxidative stress [32, 33]. Estrogen is protective against oxidative stress and increased oxidative stress parameters have been documented with reduced estrogen levels [31]. Thus, an agent that possesses the dual properties of increasing nitric oxide levels and improving antioxidant potential will be a useful therapeutic agent in reducing the risk of hypertension in the perimenopausal period.

L-arginine possesses both properties [34]. It increases the levels of NO by serving as a substrate for $\mathrm{NO}$ as well as upregulating the production of endothelial nitric oxide synthase, the enzyme responsible for conversion of L-arginine to NO [35]. Our study showed that L-arginine supplementation significantly reduced the blood pressure of perimenopausal rats. Results seen in this study was in line with previous studies that showed that oral L-arginine administration is beneficial in hypertensive patients [36-39].

Another important cardiovascular disease risk is high levels of LDL-cholesterol. Increased levels of LDL cholesterol have been reported in the perimenopausal period. This study showed that LDL was significantly higher $(\mathrm{P}<0.05)$ in VCD group compared to Control group and this supports previous reports of high levels of LDL in perimenopausal women [14]. Estrogen has been shown to produce a less atherogenic lipid profile with reduced levels of LDL and increased levels of HDL [40-42].

L-arginine administration reduced LDL levels of the perimenopausal rats to comparable levels as seen in control animals. These findings are in line with previous studies that showed the benefits of L-arginine in decreasing LDL levels [43-44]. Similarly, L-arginine supplementation significantly reduced total cholesterol levels as reported in previous studies [43-44]. 
Unlike findings with total cholesterol and LDL, there was no significant difference in the levels of HDL in the VCD and VCD + L-ARG groups. However, the HDL levels were higher in these perimenopausal groups compared to control group. This suggests that the perimenopausal period is associated with increased HDL levels. This in is line with prior studies [45-46] although other studies reported no change in HDL during the menopausal transition [14, 47 and 48]. In addition, L-arginine supplementation was associated with a significantly lower atherogenic fraction.

L-arginine has been shown to downregulate the expression of important enzymes in lipid biosynthesis such as fatty acid synthase and 3-hydroxy-3-methylglutaryl-CoA reductase [35]. On the other hand, the effect of estrogen on lipids appears to be mediated by increasing the hepatic expression of LDL receptors and decreasing abdominal lipoprotein lipase activity [49]. Although both agents act via the nitric oxide pathway, it appears that the effect of estrogen and L-arginine on lipid pathway may occur through independent pathways [34]. The interrelationship between L-arginine, estrogen and nitric oxide in lipid regulation during perimenopause is a potential area for further studies.

This study showed that L-arginine supplementation improved blood pressure and lipid profile in animal models of perimenopause. This may be protective against atherosclerosis during perimenopause [50]. Both hypertension and high levels of cholesterol are strong markers for cardiovascular disease. Lower levels of LDL have been shown to reduce the risk of atherosclerotic disease progression by causing a downregulation of inflammatory molecules responsible for this phenomenon [51-53].

\section{Conclusion}

In summary, our study supports the hypothesis that daily oral L-arginine administration is protective against cardiovascular diseases by preventing hypertension and derangement of lipid profile during perimenopause due to the L-arginine/NO pathway. However, further long-term studies are necessary to validate this hypothesis.

\section{Acknowledgements}

The authors are grateful to Mr. Taiwo Babatunde and Miss Taiwo Yewande for their technical assistance.

\section{References}

1. Angold A, Costello EJ, Worthman CM. Puberty and depression: the roles of age, pubertal status and pubertal timing. Psychol. Med., 28: 51-61, 1998.

2. Cohen LS, Soares CN, Vitonis AF, Otto MW, Harlow BL. Risk for new onset of depression during the menopausal transition: the Harvard study of moods and cycles. Arch. Gen. Psychiatry, 63: 385390, 2006.

3. Galea LA, Wide JK, Barr AM. Estradiol alleviates depressive-like symptoms in a novel animal model of post-partum depression. Behav. Brain Res., 122: 1-9, 2001.

4. McNamara M, Batur P, DeSapri KT. In the clinic, perimenopause. Ann Intern Med., 162 (3): ITC1-15, 2015. 
5. Merchenthaler I, Lane MV, Zhan M, Hoyer PB. The 4-Vinylcyclohexene Diepoxide (VCD)-Treated Rat Provides a Unique Preclinical Model to Study PeriMenopausal Hot Flushes. J Endocrinol Diabetes Obes., 2(2): 1028, 2014.

6. Koebele SV, Bimonte-Nelson HA. Modeling menopause: The utility of rodents in translational behavioral endocrinology research. Maturitas, 87: 517, 2016.

7. Mayer LP, Pearsall NA, Christian PJ, Devine PJ, Payne CM, McCuskey MK, Marion SL, Sipes IG, Hoyer PB. Longterm effects of ovarian follicular depletion in rats by 4- vinylcyclohexene diepoxide. Reprod Toxicol, 16: 775-81, 2002.

8. Reis FM, Pestana-Oliveira N, Leite CM, Lima FB, Brandão ML, Graeff FG, DelBem CM, Anselmo-Franci JÁ. Hormonal changes and increased anxietylike behavior in a perimenopause-animal model induced by 4-vinylcyclohexene diepoxide (VCD) in female rats. Psychoneuroendocrinology, 49: 130-40, 2014.

9. Couderc R, Machi M. Lipoprotein (a): risk factor for atherosclerotic vascular disease important to take into account in practice. Ann-Biol-Clin., 57(2): 157-67, 1999.

10. Rich-Edward JW, Manson JE, Hennokeni CH. The Primary prevention of coronary heart disease in women. $N$. Engl. J Med., 332(20): 1758-66, 1995.

11. Srinivas RK, Srinivasa RC. A comparative study of lipid profile and oestradiol in pre- and post-menopausal women. Journal of Clinical and Diagnostic Research, Aug, Vol-7(8): 1596-15981596, 2013.

12. Zhou J, Lin S, Shen Y, Chen Y, Zhang Y, Che F. Serum lipid profile changes during the menopausal transition in Chinese women: a community-based cohort study. Menopause, 17(5): 997 1003, 2010.

13. Derby CA, Crawford SL, Pasternak RC, Sowers M, Sternfeld B, Matthews KA. Lipid Changes During the Menopause Transition in Relation to Age and Weight. The Study of Women's Health Across the Nation. Am $J$ Epidemiol, 169: 1352-1361, 2009.

14. Al - Dahhan FH, Al - Naama LM, Disher A. Lipid Profile and Menopausal Status. Al- Kindy Col Med J, Vol .4 (1): P8-12, 2008.

15. Tousoulis D, Antoniades C, Tentolouris C, Goumas G, Stefanadis C, Toutouzas P. L-Arginine in cardiovascular disease: dream or reality? Vascular Medicine, 7: 203-211, 2002.

16. Tentolouris C, Tousoulis D, Goumas GG, Stefanadis C, Graham D, Toutouzas P. 1-arginine in coronary atherosclerosis. Int J Cardiol, 75: 123-28, 2000.

17. Li H, Forstermann U. Nitric oxide in the pathogenesis of vascular disease. J Pathol, 190: 244-54, 2000.

18. Clarkson P, Adams MR, Powe AJ et al. Oral 1-arginine improves endotheliumdependent dilation in 
hypercholesterolemic young adults. J Clin Invest, 97: 1989-94, 1996.

19. Maxwell AJ, Anderson B, Zapien MP, Cooke JP. Endothelial dysfunction in hypercholesterolemia is reversed by a nutritional product designed to enhance nitric oxide activity. Cardiovasc Drugs Ther, 14: 309-16, 2000.

20. Marchesi S, Lupattelli G, Siepi D et al. Oral 1-arginineadministration attenuates postprandial endothelial dysfunction in young healthy males. J Clin Pharm Ther, 26: 343-49, 2001.

21. Wolf A, Zalpour C, Theilmeier G et al. Dietary l-arginine supplementation normalizes platelet aggregation in hypercholesterolemic humans. J Am Coll Cardiol, 29: 479-85, 1997.

22. Panza JA, Casino PR, Badar DM et al. Effect of increased availability of endothelium-dependent vascular relaxation in normal subjects and in patients with essential hypertension. Circulation, 87: 1475-81, 1993.

23. Taddei S, Virdis A, Mattei P, Ghiadoni L, Sudano I, Salvetti A. Defective 1arginine-nitric oxide pathway in offspring of essential hypertensive patients. Circulation, 94: 1298-303, 1996.

24. Kelly JJ, Williamson P, Martin A, Whitworth JA. Effects of oral larginine on plasma nitrate and blood pressure in cortisol-treated humans. J Hypertens, 19: 263-68, 2001.

25. Mayer LP, Devine PJ, Dyer CA, Hoyer PB. The follicle-deplete mouse ovary produces androgen. Biol Reprod, 71: 1308, 2004.

26. Lohff JC, Christian PJ, Marion SL, Arrandale A, Hoyer PB. Characterization of cyclicity and hormonal profile with impending ovarian failure in a novel chemical-induced mouse model of perimenopause. Comp Med, 55: 523-7, 2005.

27. Matthews KA, Kuller LH, SuttonTyrrell K, Chang YF. Changes in cardiovascular risk factors during the perimenopause and postmenopause and carotid artery atherosclerosis in healthy women. Stroke, 32 (5): 1104-11, 2001.

28. Matthews KA, Wing RR, Kuller LH. Influence of the perimenopause on cardiovascular risk factors and symptoms of middle-aged healthy women. Arch Intern Med, 154 (20): 2349-2355, 1994.

29. Staessen JA, Celis H, Fagard R. The epidemiology of the association between hypertension and menopause. Journal of Human Hypertension, 12: 587-592, 1998.

\section{Hernandez Schulman I, and RAIJ, L.} Salt sensitivity and hypertension after menopause: role of nitric oxide and angiotensin II. Am J Nephrol, 26, 170-80, 2006.

31. Ratiani L, Khorava M, Dgebuadze M, Zhvania N, and Sanikidze T. The role of estrogens in pathogenesis of age-related arterial hypertension. Georgian Med News, 71-76, 2012.

32. Vanhoutte PM, Zhao Y, Xu A, and Leung SW. Thirty Years of Saying NO: 
Sources, Fate, Actions, and Misfortunes of the Endothelium-Derived Vasodilator

Mediator. Circ Res, 119, 375 - 396, 2016.

33. Boese AC, Kim SC, Yin KJ, Lee JP, and

Hamblin MH. Sex differences in

Vascular physiology and pathophysiology:

estrogen and androgen signaling in health

and disease. American Journal of

Physiology. Heart and Circulatory

Physiology, 313, H524-H545, 2017.

34. McIntyre M, Dominiczak AF. Nitric oxide and cardiovascular disease. Postgrad Med J, 73: 630- 634, 1997.

\section{Hong MY, Beidler J, Hooshmand S,}

Figueroa A, and Kern M. Watermelon

and L-arginine consumption improve

serum lipid profile and reduce

inflammation and oxidative stress by

altering gene expression in rats fed an

atherogenic diet. Nutr Res, 58, 46 - 54, 2018.

36. Goumas G, Tentolouris C, Tousoulis D, Stefanadis C, Toutouzas P. Therapeutic modification of the 1-arginine eNOS pathway in cardiovascular diseases. Atheroscelrosis, 154 (2): 255-67, 2001.

37. Vasdev S, Gill V. The antihypertensive effect of arginine. Int J Angiol, 17(1): 722, 2008.

\section{Asadi S, Mozaffari-Khosravi H,} Naghizade MM, Nadjarzadeh A. The Effect of Larginine Supplementation on Blood Pressure in Patients with Type 2 Diabetes: a Double-Blind Randomized Clinical Trial. Journal of Nutrition and Food Security (JNFS), 1 (1): 17-27, 2016.
39. Bahrami D, Mozaffari-Khosravi H. The effect of oral L-arginine supplementation on blood pressure in patients with metabolic syndrome: A randomized clinical trial. Iranian Journal of Diabetes and Obesity, 10(1): Spring 2018.

40. Gerhard M, Ganz P. How do we explain the clinical benefits of estrogen? From bedside to bench. Circulation, 92: 5-8, 1995.

41. Bales AC. In search of lipid balance in older women; New studies raise questions about what works best. Postgrad. Med., 108 (7): 57-72, 2000.

42. Spencer CP, Godsland H, Stevenson JC. Is there a menopausal metabolic syndrome? Gynecol. Endocrinol., 11: 34155, 1977.

43. Korbut R, Bieron K, Gryglewski RJ. Effect of L-Arginine on PlasminogenActivator Inhibitor in Hypertensive Patients with Hypercholesterolemia. The New England Journal of Medicine, 328: $287-288,1993$.

44. Stroes ESG, Koomans HA, de Bruin TWA, Rabelink TJ. Vascular Function in the Forearm of Hypercholesterolaemic Patients off and on Lipid-Lowering Medication The Lancet, 346: 467-471, 1995.

45. Poehlmam ET, Toth MJ, Ades PA, Rosen CT. Menopause - associated changes in plasma lipids, insulin - like growth factor I and blood pressure: a longitudinal study. Eur. J. Clin. Invest., 27(4): 322- 6, 1997. 
46. Everson SA, Matthews KA, Guzick DS,

et al. Effects of surgical menopause on psychological characteristics and lipid levels: the Healthy Women Study. Health - Psychol., 14 (5): 435-43, 1995.

47. Fukami K, Koike K, Hirota K, et al. Perimenopausal changes in serum lipids and lipoproteins: A seven - year's longitudinal study. Maturitas, 22(3): 1937, 1995.

48. Wakatsuki A, Sagara Y. Lipoprotein metabolism in postmenopausal and oophorectomized women. Obst. Gynecol., 85 (4): 523 - 528, 1995.

49. Tchernof A, Desmeules A, Richard C, et al. Ovarian hormone status and abdominal visceral adipose tissue metabolism. J Clin Endocrinol Metab, 89, 3425-3430, 2004.

50. Moreno JJ, and Mitjavila MT. The degree of unsaturation of dietary fatty acids and the development of atherosclerosis. Jour. of Nutri. Biochem., 14: 182 - 195, 2003.

51. Casos K, et al. Atherosclerosis prevention by a fish oil-rich diet in apoE-/- mice is associated with a reduction of endothelial adhesion molecules. Atherosclerosis, 201 (2): $306-317,2008$.

52. Ishigaki Y, et al. Impact of plasma oxidized low-density lipoprotein removal on atherosclerosis. Circulation, 118 (1): 75 $-83,2008$.

53. Kato $\mathbf{R}$, et al. Transient increase in plasma oxidized LDL during the progression of atherosclerosis in apolipoprotein E knockout mice.
Arteriosclerosis, Thrombosis, and Vascular Biology, 29 (1): 35 - 39, 2009. 